\title{
CONTRIBUIÇÕES DO CONCEITO DE PATRIOTISMO CONSTITUCIONAL PARA A ESFERA POLÍTICO-JURÍDICA BRASILEIRA
}

\author{
CONTRIBUTIONS OF THE CONCEPT OF CONSTITUTIONAL \\ PATRIOTISM FOR THE BRAZILIAN POLITICIZE-JURIDICAL SPHERE
}

Elve Miguel Cenci"

\begin{abstract}
Resumo: $\mathrm{O}$ artigo discute o conceito de patriotismo constitucional. Opondo-se à noção tradicional de nacionalismo, enfatiza a idéia da constituição como elo de ligação entre os cidadãos com base nos pressupostos do Estado democrático de direito e nos Direitos humanos. Defende a participação de todos na vida democrática com igualdade de direitos a partir de uma perspectiva universalista no interior de uma sociedade com formas de vida diversas. Por fim analisa em que aspectos o conceito é produtivo para a realidade brasileira.

Palavras-chave: Patriotismo Constitucional. Estado Democrático de Direito. Participação Democrática.
\end{abstract}

\begin{abstract}
This article discusses the concept of constitutional patriotism. Opposing itself to the traditional notion of nationalism, it emphasizes the idea of constitution as a link among citizens based on the presuppositions of the Democratic state of rights as well as in the Human Rights. It defends everyone's participation in the democratic life with equality of rights based on a universalist perspective within a society with different forms of life. It also analyses in which aspects the concept is productive for the Brazilian reality.
\end{abstract}

Keywords: Constitutional Patriotism. Democratic Participation.

\section{INTRODUÇÃO}

Já se tornou lugar comum falar que nas últimas décadas o mundo passou por mudanças profundas. Acontecimentos como o fim da guerra fria, a queda do muro de Berlim e a reunificação alemã, a União Européia, conflitos étnicos, o fenômeno da globalização e outros acontecimentos, muitos deles ainda em curso, são altamente significativos para o nosso tempo. Essas questões exigem de

"Doutor pela UFRJ. Docente do Mestrado em Direito Negocial/UEL. 
sociólogos, filósofos, juristas, economistas, politicólogos e demais pensadores, respostas complexas para problemas que são igualmente complexos. Como superar o velho problema do nacionalismo étnico que opõe culturas e povos e que em muitos casos vê o outro, por ser diferente, como inimigo? Como pensar formas de convivência em sociedades complexas e não homogêneas? Em um universo plural, que princípios devem pairar acima das particularidades, não apenas no âmbito local mas também supranacional?

As reflexões que guiarão este artigo têm como horizonte de referência a obra do filósofo e sociólogo alemão Jürgen Habermas. Sua obra é marcada por volumosos e densos textos sobre temas morais, políticos e jurídicos, como é o caso da Theorie des Kommunikativen Handelns (2v.) e Faktizität und Geltung, mas também por artigos, geralmente publicados nos grandes jornais da Europa, que tratam sobre problemas da atualidade. Em situações de conflito, como a invasão americana no Iraque ou a intervenção na região do Kosovo, em temas polêmicos como eugenia ou projetos como a União Européia, sua voz se faz ouvir. Conciliando o diálogo sobre autores clássicos com problemas contemporâneos, sua obra se firma como a mais importante entre os filósofos vivos.

A partir dos anos de 1980, a produção acadêmica de Habermas se volta para questões relacionadas à filosofia prática, com destaque para a elaboração, em parceria com Apel, da ética do discurso. Esse caminho teórico terá novo desdobramento no início da década de 1990 com uma guinada jurídica, que é resultado da aplicação da teoria do 'agir comunicativo' ao direito e gera uma 'teoria discursiva do direito'. O direito aparece vinculado à ética discursiva e culmina no tema da democracia, isto é, desempenha o papel de "categoria mediadora entre a facticidade da política e da economia e a pretensão de validade normativa da moral” (ARROYO, 2000, p. 79). Nesse entrelaçamento do debate entre questões políticas, jurídicas e morais é que se insere o conceito de 'patriotismo constitucional' (Verfassungspatriotismus).

\section{PATRIOTISMO CONSTITUCIONAL E NACIONALISMO: UM OLHAR A PARTIR E PARA ALÉM DO CASO ALEMÃO}

O estudo do conceito de "patriotismo constitucional” exige que se analise, mesmo que brevemente, a concepção tradicional de nacionalismo. Habermas descreve o nacionalismo da forma como este se estruturou no final do século XVIII e que representa uma ruptura em relação ao antigo regime, como dotado de certas características:

Em primeiro lugar, no nacionalismo as idéias fundadoras da identidade provém de uma herança profana, independente da Igreja e da religião, herança 
que veio preparada e mediada pelas ciências do espírito, que nascem nesse momento. Isto explica algo do caráter penetrante e consciente dessas idéias. Se apoderam quase que da mesma forma de todos os segmentos da população e dependem de uma forma autoativadora e reflexiva de apropriação da tradição. Segundo, o nacionalismo faz coincidir a herança cultural comum da linguagem, literatura ou história, com a forma de organização que representa o Estado. O Estado nacional democrático, surgido da Revolução francesa, é o modelo pelo qual se orientam todos os movimentos nacionalistas. Terceiro, na consciência nacional se dá uma tensão entre dois elementos, que nos Estados nacionais clássicos, quer dizer, nas nações que somente cobraram consciência de si nas formas de organização estatal com que já se encontravam, guardam uma relação de mais ou menos equilíbrio. Me refiro à tensão entre as orientações universalistas do valor do Estado de Direito e a democracia, por um lado, e o particularismo de uma nação que se delimita a si mesma diante do mundo externo, por outro. (HABERMAS, 1998, p. 89-0).

Ao longo da história, o conceito de nação amparado nos pressupostos do nacionalismo se mostrou eficiente ao agregar e criar o sentimento de pertencer compartilhado com outros ${ }^{1}$. Como forma de construção da identidade coletiva, o apelo nacionalista, por se amparar em um sentimento e não fundamentalmente na argumentação racional, alcançou uma força de adesão maior do que o recurso a um 'patriotismo da constituição'. Nesse sentido é interessante conhecer o caso da Alemanha, que passou pelas duas experiências.

Com o fim da II ${ }^{\circ}$ Guerra, a Alemanha estava buscando uma nova identidade que a distanciasse do Nazismo. Passados 30 anos, o historiador Dolf Sternberg ${ }^{2}$

1 "os diversos movimentos nacionalistas - alguns com enorme poder convocatório - se autoconcebem em termos de homogeneidade cultural (seja étnica, lingüística, religiosa ou cosmovisional) e em termos de crítica às formas abstratas e neutras do poder político de mediação de caráter supranacional”. (ARROYO, 2000, p. 197).

${ }^{2}$ As constantes referências à Alemanha se devem ao fato de que o conceito de 'patriotismo constitucional' (Verfassungspatriotismus) teve sua origem naquele país por ocasião dos 30 anos da Constituição alemã de 1949 (Lei Fundamental de Bonn). Ao que tudo indica, o primeiro autor a usar o termo tenha sido Dolf Sternberger, mas foi sobretudo com Jürgen Habermas que adquiriu ampla publicidade no meio acadêmico e político. O objetivo de Sternberger ao introduzir o conceito era "destacar a capacidade que a Lei Fundamental de Bonn havia demonstrado para inspirar de forma democrática a cultura política alemã e para configurar uma nova identidade coletiva. Pretendia desse modo não só contribuir pedagogicamente para a formação política das novas gerações, mas também indicar uma categoria descritiva que desse conta do tipo de identidade coletiva desenvolvido na Alemanha ocidental, mesmo podendo ser estendido a outras sociedades complexas”. (ARROYO, 2000, p. 199). O assunto voltou à tona novamente 
observou que a República Federal havia adotado o caminho de um patriotismo da constituição, que teve como resultado "uma identificação com a ordem política e os princípios constitucionais" (HABERMAS, 1998, p. 94). Esse tipo de patriotismo produziu de forma reflexiva uma identidade política coletiva sintonizada não mais com a idéia de supremacia, mas com uma perspectiva universalista comprometida com os princípios do Estado constitucional democrático ${ }^{3}$. No patriotismo constitucional, a identificação

só surge depois que cultura e política do Estado tenham se diferenciado de forma mais radical do que nos Estados nacionais no velho formato. Neste caso as identificações com as formas de vida e tradições próprias ficam recobertas por um patriotismo mais abstrato, que não se refere já ao todo concreto de uma nação, mas a procedimentos e a princípios abstratos. E estes se referem, por sua vez, às condições de convivência e comunicação de formas de vida diversas, com iguais direitos, coexistentes - tanto no interior como exterior -. A vinculação a esses princípios, que o patriotismo constitucional fomenta, há de nutrir-se da herança de tradições culturais consonantes. As tradições nacionais seguem produzindo todavia uma forma de vida que ocupa um lugar privilegiado, se bem que apenas em uma hierarquia de forma de vida de raio e alcance diversos. A estas formas de vida correspondem, por sua vez, identidades coletivas que se solapam umas com as outras, porém que já não necessitam de um ponto central onde tenham que assegurar-se e integrar-se formando a identidade nacional. Em vez disso, a idéia abstrata de universalização da democracia e dos direitos humanos constitui a matéria dura em que se refratam os raios das tradições nacionais - linguagem, literatura e a história - da própria nação. (HABERMAS, 1998, p. 101-2).

A perspectiva universalista do patriotismo constitucional aparece como contrapartida para a superação do nacionalismo extremado, como no caso da

com força nos anos de 1980 na "disputa entre historiadores" sobre a autocompreensão da Alemanha acerca do seu passado autoritário. Foi ao opinar sobre esse debate que Habermas pela primeira vez usou o termo.

${ }^{3}$ Para Habermas a idéia de 'patriotismo constitucional' significa na Alemanha "o orgulho de ter conseguido superar duradouramente o fascismo, estabelecer um Estado de Direito e apoiar este numa cultura política que, apesar de tudo, é mais ou menos liberal. Nosso patriotismo não pode negar o fato de que na Alemanha a democracia, apenas após Auschwitz (e de certo modo apenas após o choque dessa catástrofe moral), pode deixar suas raízes nos motivos e nos corações dos cidadãos ou, pelo menos, das jovens gerações. Para esse enraizamento de princípios universalistas é preciso sempre uma determinada identidade”. (HABERMAS, 1998, p. 115-6). 
Contribuições do conceito de patriotismo constitucional para a esfera político-jurídica...

Alemanha ${ }^{4}$, ou também nos outros Estados europeus que aos poucos foram tornando relativo o Estado-nação e passaram a olhar na direção de um projeto pós-nacional. Esse universalismo, que é moral, consiste em um processo onde as formas de vida são relativisadas em comparação umas com as outras e passa a vigorar o princípio da tolerância em relação aos demais e suas particularidades.

Para que a perspectiva universalista possa se materializar concretamente para além meramente de uma moral formal e ser formadora de identidade, seus princípios devem firmar raízes nas culturas políticas específicas de cada país. Dessa forma os princípios do Estado de Direito e da vida democrática poderão se tornar algo concreto de acordo com a história e a cultura de cada povo. $\mathrm{Ou}$ seja, à medida que se pensa o mundo a partir de uma perspectiva comum, respeitando-se as particularidades locais, é possível se formar uma "identidade coletiva" efetiva, real.

Apesar de ter sido amplamente utilizado no debate alemão na querela entre os historiadores, o conceito de patriotismo constitucional pode contribuir significativamente para outros povos e contextos, inclusive no caso brasileiro. Em primeiro lugar, esse conceito está diretamente relacionado à perspectiva republicana. Já nasceu da tentativa de responder a questões como por exemplo:

a) como dotar de uma nova identidade coletiva uma comunidade política que experimentou uma ruptura na continuidade de sua própria história; b) quais podem ser os aspectos de identidade compartilhados por uma sociedade marcada por um profundo pluralismo cultural; e c) sobre que bases comuns se poderia assentar a identidade da União Européia ainda em processo de construção. (ARROYO, 2002, p. 33).

Como já destacado, após a experiência nazista a Alemanha necessitava de novos princípios constitucionais para estruturar a política, porém princípios sólidos que gerassem uma identidade coletiva e uma "cultura política

4 "O nacionalismo foi extremado entre nós [Alemanha] em termos de darwinismo social e culminou em um delírio racial que serviu de justificação para a aniquilação massiva dos judeus. Por isso o nacionalismo ficou drasticamente desvalorizado entre nós como fundamento de uma identidade coletiva. Daí também que a superação do fascismo constitua a perspectiva particular histórica a partir da qual entre nós é entendida uma identidade pós-nacional, cristalizada em torno dos princípios universalistas do Estado de Direito e da democracia. Mas não só a República Federal da Alemanha: todos os países europeus evoluíram após a II Guerra Mundial, de sorte que o plano de integração que representa o Estado nacional perdeu peso e importância”. (HABERMAS, 1998, p. 116-7). 
democrática”. Ao cunhar o conceito, Sternberger queria destacar uma nova perspectiva que aos poucos foi se estruturando não mais com base em pressupostos "étnico-culturais" ou por um "passado glorioso", mas pela participação democrática com respaldo na constituição.

O patriotismo de Sternberger tem um sentido bastante preciso

não se refere a um determinado texto constitucional, mas aos valores que possui e sob os quais os indivíduos se convertem em cidadãos livres e iguais diante da lei. A constituição consagra um espaço político de liberdade no qual, abandonando a condição de súditos, os homens se tornam cidadãos e protagonistas da gestão e custódia dos assuntos públicos. O objeto que suscitaria 'devoção patriótica' e lealdade política não é o documento jurídico em sua literalidade mas a "ordem democrática e liberal” que precisamente a constituição funda e protege. Se incorre, portanto, em um uso interessado e bastante deslocado do 'patriotismo constitucional' quando este se transforma em um tipo de "fundamentalismo constitucional". (ARROYO, 2002, p. 38).

Essa advertência em relação ao texto constitucional afasta qualquer perspectiva 'sagrada' e o torna mais próximo do mundo real do dia-a-dia com suas peculiaridades. Além disso, a constituição deve servir como meio dinâmico de integração.

Habermas partilha da tese de Sternberger de que o patriotismo constitucional está sintonizado com a perspectiva republicana. As noções de autogoverno e patriotismo geram a compreensão de que os cidadãos se identificam com os interesses da sua comunidade. Quando acontece algum problema envolvendo o governo ou as instituições, surge a indignação cívica. O desafio para se obter coesão numa perspectiva republicana em uma sociedade com formas de vida e culturas distintas é maior. Como construir unidade política na diversidade de perspectivas e olhares sobre o mundo? Novamente o ponto de união deve ser buscado nos pressupostos democráticos ${ }^{5}$ e nos direitos humanos, ou seja, no

5 "A democracia seria, de acordo com os pressupostos habermasianos, aquele modelo político no qual a legitimidade das normas jurídicas e das decisões públicas radicaria em terem sido adotadas com a participação de todos os potencialmente afetados por elas. Porém a intuição mais genuína da concepção deliberativa da democracia consiste na afirmação de que, chegado o momento de adotar uma decisão política, o seguimento da regra da maioria há de subordinar-se ao prévio cumprimento do requisito de uma discussão coletiva capaz de oferecer a todos os afetados a oportunidade de defender publicamente seus pontos de vista e seus interesses mediante argumentos genuínos e negociações limpas. A deliberação em nenhum caso deve confundir-se com a mera 
Estado democrático de direito em sintonia com uma perspectiva supranacional. É importante destacar que a união em torno de aspectos culturais e étnicos não é desconsiderada, apenas que os princípios democráticos são mais acentuados como elo de ligação. O vínculo entre os diversos grupos poderá se dar, portanto, com base nesses princípios coexistindo com a diversidade e com as diferenças, o que em tese permite uma cultura da tolerância.

Uma objeção que poderia ser feita ao patriotismo constitucional é a de que por si só princípios políticos não conseguem consolidar uma identidade coletiva por serem demasiado abstratos. No entanto, essa noção se ampara em aspectos bem concretos à medida em que na vida prática o funcionamento das instituições, procedimentos e hábitos de como deliberar comuns a todos formam uma "cultura política vivida”. A própria autocompreensão e formação da identidade passa a ser pensada em sintonia com práticas reais na diversidade de perspectivas culturais. O elo comum deve residir na convivência sob os mesmos princípios do Estado democrático de direito.

A proposta habermasiana é uma forma de "cultura política" que materializa o sistema de direitos concretamente numa comunidade sob a ótica pós-nacional, sem desqualificar os aspectos culturais locais. Sem a perspectiva universalista, corre-se o risco de incorrer nos velhos problemas identificados no nacionalismo, isto é, pode-se recair no particularismo com os riscos associados; sem o solo concreto de um ou mais grupos culturais dando suporte, corre-se o risco de ser algo excessivamente abstrato. Portanto, os dois aspectos são imprescindíveis para que se tenha um "patriotismo cívico".

Uma nação de cidadãos que se identificam na participação igualitária nos direitos democráticos, gerando uma cultura cívica em favor da democracia, funciona como antídoto para o desenvolvimento e acirramento dos particularismos presentes nas formas de vida específicas. Como destaca Arroyo (2002, p. 36), o que se exige dos participantes do Estado democrático é que passem por um processo de "aculturação política", já que a identidade coletiva não se dá com base na homogeneidade das práticas culturais.

ratificação coletiva de posições já cristalizadas. Se todas as preferências e opiniões políticas precisam ser submetidas a um processo de debate e esclarecimento mútuos, isto implica que todos os atores políticos devem estar abertos a mudar sua posição inicial se como resultado da deliberação política encontrarem razões para fazê-lo. Se essa atitude não está presente, a discussão fica como um mero trâmite que terá que ser cumprido antes de proceder a votação, isto é, de aplicar mecanicamente o poder da maioria”. (ARROYO, 2003, p. 10-1). 


\section{PATRIOTISMO CONSTITUCIONAL E UNIÃO EUROPÉIA}

Como é possível notar, as constantes referências a uma perspectiva pós-nacional e universalista feitas por Habermas trazem como pano de fundo as discussões européias, tanto o processo pelo qual passou a Alemanha com a reunificação após a queda do muro de Berlim, quanto a estruturação da União Européia e a proposta em andamento de uma constituição. Ou seja, o projeto de união de vários Estados da Europa, inclusive em direção ao leste, exige a conciliação das diferenças, medos e particularidades locais em favor de um projeto comum pensado para todos, portanto supranacional. No caso da Alemanha, o velho nacionalismo totalitário do nazismo deu lugar a um novo projeto, que hoje é compartilhado com os vizinhos no desafio comum de construir uma Europa baseada em pressupostos democráticos e respeito pelos direitos humanos. É interessante destacar que mesmo sem a aprovação da constituição, aspectos que historicamente foram considerados como pertencentes à soberania dos Estados deixaram de existir. É o caso da moeda local, que foi substituída por uma única e também o mercado comum, além de outros pontos já acordados pelos Estados membros. $\mathrm{O}$ debate europeu recente tem discutido quais competências permanecem com os Estados e o que se torna, após deliberação, válido para todos.

Sobretudo a partir do final dos anos de 1990, Habermas passa a discutir problemas relacionados ao processo de consolidação da União Européia, como é o caso da proposta de uma constituição. Seus textos apontam para a necessidade de uma "cultura política" comum que possa debater os temas de interesse de todos e, também, para o aprimoramento democrático das instituições, uma vez que as decisões tomadas em Bruxelas nem sempre repercutem de forma satisfatória ${ }^{6}$.

As deficiências democráticas só podem ser eliminadas a partir do momento em que se formar um espaço público democrático europeu. Em sociedades complexas, a legitimação democrática surge do jogo conjunto de processos institucionalizados de deliberação, de decisão e de formação informal da opinião através dos meios de comunicação de massa nas arenas da comunicação pública. Ou seja, no Estado democrático de direito, a infraestrutura do espaço público preenche uma função ideal, a saber, a transformação de problemas relevantes, em nível de sociedade global, em

\footnotetext{
${ }^{6}$ Ver sobretudo a obra Era das Transições (2003) e o artigo "A imaginação contra o poder", publicado no Brasil no jornal "Folha de São Paulo" sobre o NÃOdos franceses à proposta de uma constituição para a Europa (2005).
} 
núcleos cristalizadores de discursos, permitindo que os cidadãos se refiram simultaneamente aos mesmos temas importantes e tomem posição em relação a temas controversos, dizendo "sim" ou "não". (HABERMAS, 2001, p. 140).

O que falta é uma opinião pública efetivamente européia para que os assuntos comuns possam ser discutidos, por exemplo, em cada periódico local mas como se fosse uma grande opinião pública. $O$ problema é que ainda não existe esse debate, funcionando apenas como a soma das opiniões públicas locais. Não há no entendimento de Habermas "um espaço público europeu" e a constituição poderia funcionar como referência de princípios políticos comuns.

Os críticos dessa proposta afirmam que não existe algo como um "povo europeu" que sirva de base para o projeto da constituição. Contra eles Habermas argumenta que não há a necessidade da existência de uma identidade étnicocultural mas sim a decisão democrática de construir uma unidade política. $\mathrm{Ou}$ seja, os cidadãos europeus dependem mais de vontade política para deliberarem discursivamente acerca do projeto que querem para si do que propriamente de uma "identidade" comum nos moldes tradicionais. Mas para que esse debate possa efetivamente ocorrer, é importante a formação de uma esfera pública que funcione sintonizada com um projeto político comum. O poder propulsor da constituição pode efetivar esse "processo", uma vez que a existência de instituições políticas pode representar o elo de ligação necessário de que a Europa necessita.

Em meio à enorme pluralidade, Habermas acredita que pode se originar uma cultura política para toda a Europa, o que estaria em sintonia com a idéia de um patriotismo constitucional. É interessante destacar que efetivamente houve um crescimento do debate no interior dos Estados membros sobre temas comunitários pelo aumento do número e a importância dos assuntos políticos comuns. As definições sobre questões jurídicas, moeda, passaporte, etc, formam aos poucos uma identidade comum que funciona sintonizada com as identidades nacionais. Esse projeto no entanto corre riscos de involução se, por exemplo, restringir-se a questões de mercado numa atitude de defesa ou aderir à ótica neoliberal.

\section{PATRIOTISMO CONSTITUCIONAL E CULTURA POLÍTICO-JURÍDICA BRASILEIRA $^{7}$}

Mais do que copiar fórmulas ou modelos, o que o texto apresenta pode servir de referência para pensarmos a nossa própria realidade. Para além das particularidades específicas da Europa, a defesa do Estado democrático de direito

${ }^{7}$ A expressão “cultura político-jurídica brasileira” é do Prof. Dr. Antonio Maia Cavalcanti. 
e dos direitos humanos vale para todos os povos. De forma concreta, essa tese significa reconhecimento e respeito pelas formas culturais, senso de pertença às instituições do Estado de direito e justa distribuição de renda. Como destaca Arroyo (2000, p. 202),

o pressuposto básico para um harmônico desenvolvimento democrático de uma sociedade não é, contudo, a homogeneidade cultural, mas a igualdade do status legal entre todos os membros e, sobretudo, um certo grau de homogeneidade socioeconômica. As diferenças no nível de riqueza estão intimamente relacionadas com os fenômenos inclusão/exclusão sociopolítica.

Mesmo sem uma análise mais detalhada, basta um breve passeio pela nossa Carta Magna para percebermos que a Constituição brasileira está em sintonia com as três teses elencadas. Já no preâmbulo, o texto destaca o objetivo de "instituir um Estado Democrático, destinado a assegurar o exercício dos direitos sociais e individuais, a liberdade, a segurança, o bem-estar, o desenvolvimento, a igualdade e a justiça como valores supremos de uma sociedade fraterna, pluralista e sem preconceitos". Na seqüência, no Art. 1aa, a ênfase é clara quanto à defesa do Estado democrático de direito. Percebe-se o destaque para aqueles que são considerados os fundamentos desse modelo de Estado tais como "soberania, cidadania, dignidade, pluralismo...”. Ao discutir os objetivos fundamentais, no Art. 3a , o texto constitucional prescreve: "construir uma sociedade livre, justa e solidária, erradicar a pobreza e a marginalização e reduzir as desigualdades sociais e regionais. Promover o bem de todos sem preconceitos de origem, raça, sexo, cor, idade...". No Art. 4ㄹ, encontramos o comprometimento com os direitos humanos, igualdade entre os Estados, paz e, claramente numa perspectiva cosmopolita, uma referência à "cooperação entre os povos para o progresso $d a$ humanidade". Adiante, no Art. 5a , ao tratar sobre os direitos e garantias fundamentais, o destaque é para a idéia de igualdade perante a lei, liberdade, etc, com ênfase para a relação de gênero.

Porém, se a Constituição defende o Estado de Direito, a pluralidade e a redução das desigualdades em sintonia com uma perspectiva cosmopolita, há uma distância em relação ao mundo real. Em primeiro lugar, em uma escala mundial figuramos como um dos piores países na distribuição de renda. Segundo, nem sempre as práticas na sociedade são democráticas. Na nossa história recente temos como exemplo denúncias de corrupção, violação da cidadania e dos direitos fundamentais, sem entrar em questões mais específicas no âmbito institucional ${ }^{8}$,

${ }^{8} \mathrm{O}$ recurso às medidas provisórias deixou de ser um importante instrumento para casos de "relevância e urgência" para se tornar quase que a regra. 
como por exemplo o desrespeito à separação dos poderes. Tais fatos em muitos casos provocam indignação e desconfiança no regime democrático. Há algum tempo uma pesquisa demostrou que uma parcela expressiva da população brasileira trocaria a democracia por uma ditadura militar por acreditar que um regime de exceção poderia resolver com mais competência dois problemas sérios do nosso tempo: segurança e corrupção. Como é sabido, o regime de exceção viola exatamente os dois pilares da noção de patriotismo apresentada nesse texto.

Se nem sempre o que está posto na constituição ocorre na vida real, o único caminho para a superação dessa dicotomia passa pela via democrática. No entanto, a vida democrática não apresenta soluções mágicas, mas é exigente pois pressupõe um processo gradual de aprendizagem para que as pessoas possam se tornar sujeitos e fazerem suas escolhas. Um bom começo pode ser reagindo com "indignação cívica" diante das afrontas à constituição.

Contra um século XX pouco democrático e a distância existente entre o texto constitucional e a realidade, vale o princípio básico já ressaltado de que a democracia é construção. Isso significa dizer que a materialização de noções aparentemente abstratas como igualdade, liberdade, justiça, direitos, pluralismo, ausência de preconceitos, depende de processos reais que ocorrem mediante deliberação. Uma sociedade mais ou menos democrática não resulta de um processo alheio à vontade das pessoas, mas de escolhas políticas feitas pelos seus membros. A participação dos cidadãos afetados pelas conseqüências das decisões deve ocorrer de fato, pois a regra da maioria deve estar subordinada a práticas idôneas levadas adiante no espaço público mediante a apresentação de bons argumentos. É importante destacar que opiniões e interesses não são ilegítimos, desde que publicizados com argumentos racionalmente defensáveis. Portanto, sem esse procedimento descrito, a discussão vira mera formalidade antes das votações para que se cumpra meramente o procedimento. Em tese, com o modelo representativo isso acontece através da ação dos legisladores; o problema é que a democracia é mais exigente do que os procedimentos formais indicam. Deliberação não se confunde apenas com ratificação mas tem a ver com debate, esclarecimento e transparência. Os pressupostos que estão na base dessa concepção de democracia que delibera com a participação dos afetados, onde só valem bons argumentos, sem a possibilidade da coação, onde os participantes devem estar dispostos a mudar suas posições diante de um argumento racionalmente fundamentado, são morais. 


\section{REFERÊNCIAS}

ARROYO, Juan Carlos V. La teoría discursiva del derecho. Sistema jurídico y democracia en Habermas. Madrid: Centro de Estudios Políticos y Constitucionales, 2000.

Acerca de la democracia deliberativa. Fundamentos teóricos y propuestas prácticas. Madrid: Revista Parlamentaria de la Asamblea de Madrid, Asamblea de Madrid, 2003.

. Patriotismo constitucional y republicanismo. Claves de razón practica, $\mathrm{n}^{\mathrm{a}}$ 125, 2002.

BRASIL. Constituição da República Federativa do Brasil: promulgada em 5 de outubro de 1988. 33 ed. atual. e ampl. São Paulo: Saraiva, 2005.

CAVALCANTI, Antonio Maia. A idéia de patriotismo constitucional e sua integração à cultura político-jurídica brasileira. In: Habermas em discussão. Anais do Colóquio Habermas. PINZANI; Alessandro; DUTRA, Delamar J. V. (Org.). Florianópolis: NEFIPO, 2005.

HABERMAS, Jürgen. Theorie des Kommunikativen Handelns (2v.). Frankfurt am Main: Suhrkamp, 1981. (Trad. Teoria de la acción comunicativa. (2 v.) Madrid: Taurus, 1987/1989.

. Die Einbeziehung des Anderen. Frankfurt am Main: Suhrkamp, 1996. (Trad. A inclusão do outro. São Paulo: Loyola, 2002)

. Faktizität und Geltung: Beiträge zur Diskurstheorie des Rechts und des demokratischen Rechstaats. Frankfurt am Main: Suhrkamp, 1992. (Trad. Direito e democracia: entre facticidade e validade. Rio de Janeiro: Tempo Brasileiro, 1997.

. Die postnationale Konstellation. Politische Essays. Frankfurt: Suhrkamp, 1998 (Trad. A constelação pós-nacional. São Paulo: Littera Mundi, 2001.

. Pourquoi l'Europe a-t-elle besoin d'un cadre constitutionnel ? Disponível em: <http://www.unice.fr/urmis-soliis/Docs/Cahiers_7/cahiers_n7_ habermas.pdf\#search='Pourquoi l'Europe habermas'>. Acesso em: 28 fev. 2005.

. Si, voglio una Costituzione per l'Europa federale. Disponível em: <http:/ /www.caffeeuropa.it/attualita/112attualita-habermas.html>. (Trad. Sim, quero uma constituição para a Europa Federal. Crítica, Londrina, v. 6, n. 23, abr./jun 2001.) 
Contribuições do conceito de patriotismo constitucional para a esfera político-jurídica... . Identidades nacionales y postnacionales. Madrid: Tecnos, 1998. . Era das transições. Rio de Janeiro: Tempo Brasileiro, 2003. . A imaginação contra o poder. Folha de São Paulo, 12 jun. 2006. Caderno Mais. Disponível em <www1.folha.uol.com.br/fsp/mais/fs1206200504.htm>. Acesso em: 15 jul. 2005. 